\title{
Síndrome de Marfan e Dissecção Carotídea Bilateral
}

\author{
Roberto Magalhães Carneiro de Oliveira*
}

\begin{abstract}
RESUMO
A síndrome de Marfan é uma doença do tecido conectivo de herança autossômica dominante, que afeta os ossos, os olhos, os pulmões e o sistema cardiovascular. Relatamos o caso de um rapaz de 16 anos com síndrome de Marfan que apresentou infarto frontoparietal direito. A angiografia cerebral mostrou oclusão de artéria carótida interna esquerda e estenose da artéria carótida interna direita, com padrão de dissecção próximo à sua origem. Ressaltamos a importância de se investigar doenças do tecido conjuntivo em pacientes jovens com dissecção arterial mesmo na ausência de história familiar.
\end{abstract}

\section{UNITERMOS}

Síndrome de Marfan, dissecção arterial.
Neurologista do Setor de Doenças Neurovasculares da Unifesp-EPM

\section{NTRODUÇÃO}

A síndrome de Marfan é um distúrbio generalizado do tecido conjuntivo, com acometimento de diferentes órgãos, e manifestações oculares, cardíacas, esqueléticas, pulmonares e neurológicas ${ }^{1}$. A prevalência da síndrome de Marfan na população é de, aproximadamente, 1 para 10.000 habitantes. A herança é autossômica dominante, muito embora $15 \%$ a $30 \%$ dos casos representem nova mutação ${ }^{2}$. Alguns autores acreditam que a herança seja autossômica recessiva ${ }^{3}$. Há, geralmente, uma grande variação clínica entre os membros afetados de determinada família. Uma série de manifestações neurológicas já foram descritas em pacientes com síndrome de $\mathrm{Marfan}^{4}$, desde alterações vasculares cervicais e espasmo hemifacial ${ }^{5}$ até apnéia do sono ${ }^{6,7}$. Apresentamos o caso de um paciente jovem com síndrome de Marfan e infarto cerebral, em quem diagnosticamos dissecção carotídea espontânea bilateral.

\section{RELATO DE CASO}

Paciente do sexo masculino, branco, de 16 anos de idade, enquanto trabalhava, apresentou sensação de dormência na mão esquerda, seguida de paresia súbita e lentamente progressiva de todo o membro superior esquerdo, acompanhada de discreta dor cervical direita. Não havia relato de traumatismo cervical ou de movimento brusco cervical. Os déficits começaram a melhorar após 48 horas, permanecendo hemiparesia esquerda com moderada limitação e espasticidade. Antecedentes pessoais de subluxação de cristalino com facectomia bilateral; amaurose fugaz à esquerda há 7 anos e pneumotórax espontâneo drenado há 2 meses. Antecedentes familiares negativos para síndrome de Marfan, doenças osteoarticulares ou morte súbita. Ao exame clínico, mostrava pectus excavatum, aracnodactilia e articulações alargadas. Apresentava postura espástica de mão esquerda, com rigidez e hiper-reflexia em membros à esquerda. $\mathrm{O}$ ecodopplercardiograma revelou prolapso de válvula mitral sem repercussões hemodinâmicas. A tomografia computadorizada e a ressonância magnética de crânio (Figura 1) revelaram infarto frontoparietal direito. A angiografia cerebral mostrou oclusão de artéria carótida interna 


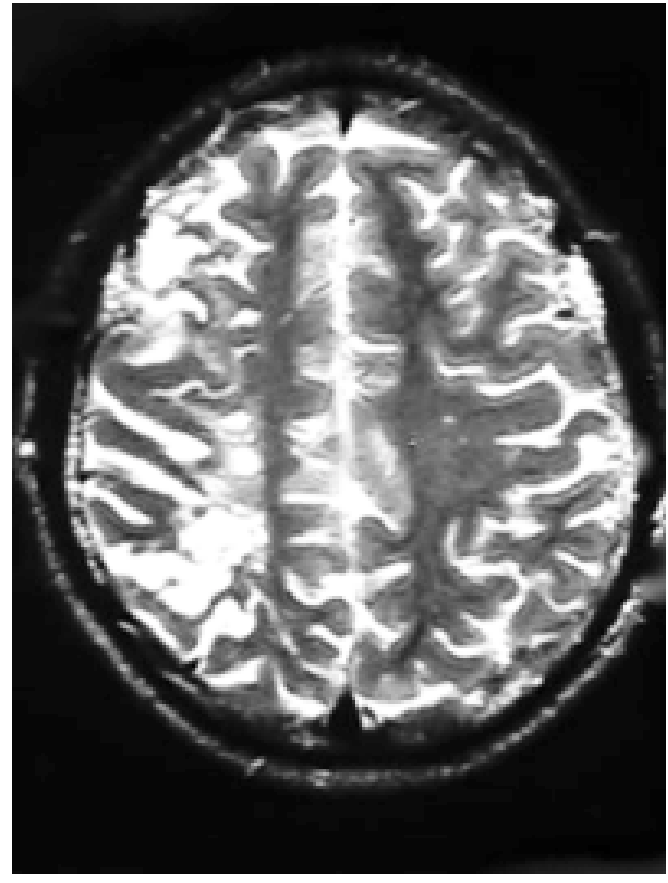

FIGURA 1

Ressonância magnética de crânio $\left(\mathrm{T}_{2}\right)$ em corte axial mostrando áreas de infarto em região frontal e parietal direita.

esquerda, próximo ao bulbo carotídeo (Figura 2) e estenose da artéria carótida interna direita com padrão de dissecção espontânea (Figura 3); artérias vertebrais tortuosas e dilatadas suprem o território carotídeo bilateral pelas artérias comunicantes posteriores; o arco aórtico e o tronco braquiocefálico foram normais. Apesar das grandes alterações vasculares na angiografia cerebral, o paciente apresentava poucos sinais e sintomas, pois o território carotídeo era suprido pela circulação posterior.

\section{DISCUSSÃO}

A primeira descrição de dissecção espontânea da artéria carótida interna foi feita em $1915^{8}$. Desde então, centenas de casos têm sido relatados e associados a diferentes etiologias. Uma série de arteriopatias primárias tem sido relacionada ao desenvolvimento de dissecção arterial cervical, incluindo aquelas associadas com doenças do tecido conjuntivo hereditárias (síndrome de Ehlers-Danlos, síndrome de Marfan, pseudoxantoma elástico, doença policística renal e deficiência de alfa1 -antitripsina) ${ }^{9}$.

Em 1896, no Bulletin of the Medical Society de Paris, o pediatra Antoine Bernard Marfan descreveu o caso de uma menina de 5 anos com aracnodactilia ${ }^{10}$. A síndrome, que leva seu nome, foi mais tarde relacionada a uma série de anomalias, todas relacionadas ao tecido conjuntivo. Hoje, conhecemos a síndrome de Marfan como um distúrbio do tecido conjuntivo de herança autossômica dominante, apresentando grande variação fenotípica. É justamente essa variação fenotípica e a ocorrência de novas mutações que permitem que tenhamos pacientes com síndrome de Marfan sem história familiar, como o caso apresentado.

O substrato anatômico da síndrome de Marfan é a degeneração das fibras elásticas e a desorganização do colágeno. A base molecular do defeito da síndrome de Marfan foi apenas recentemente elucidado. A proteína microfibrilar, denominada fibrilina, foi descoberta em $1986^{11}$. As alterações na síndrome de Marfan são decorrentes da mutação de genes localizados no cromossomo $15^{12,13}$. O FBN1 codifica a principal proteína constituinte do tecido elástico: fibrilina 1, presente principalmente nas estruturas que devem resistir à tensão e ao estresse (adventícia da aorta, o ligamento suspensor do cristalino, pele). A fibrilina 1 é o principal constituinte das microfibrilas extracelulares. Estas podem existir como estruturas isoladas ou associadas com a elastina para formar as fibras elásticas ${ }^{14}$. O segundo gene (FBN2) é responsável pela orientação da elastina e, principalmente, presente na cartilagem, na camada média da aorta, nos brônquios e em todos os tecidos ricos em elastina. As mutações da FBN1 são bastante comuns e estão associadas não apenas com a síndrome de Marfan, mas também com as fibrilinopatias: formas incompletas, formas neonatais, ectopia de cristalino e aneurisma isolado da aorta torácica. A distribuição difusa das fibrilinas explica a natureza pleiotrópica da síndrome de Marfan e de suas apresentações clínicas. A variabilidade da expressão interfamiliar é devida à heterogeneidade genética (ao menos dois genes) e às diferenças alélicas (diferentes mutações da FBN1 de uma família para outra), também explicando formas leves devido à redução quantitativa na fibrilina normal e formas intensas por dominância negativa em que a fibrilina é estruturalmente anormal por alteração do mecanismo de polimerização. Desde 1991, mais de 150 mutações foram descritas no gene que é crítico na produção da estrutura da proteína fibrilina ${ }^{15}$.

Várias são as propostas de critérios diagnósticos para a síndrome de $\operatorname{Marfan}^{16}$. A maioria delas é baseada nos achados clínicos e inclui anormalidades musculoesqueléticas, subluxação de cristalino, miopia e aneurisma de aorta. As alterações esqueléticas podem ser facilmente reconhecidas, tais como elevada estatura, aracnodactilia ou dolicostenomelia, prognatismo, palato arqueado, 


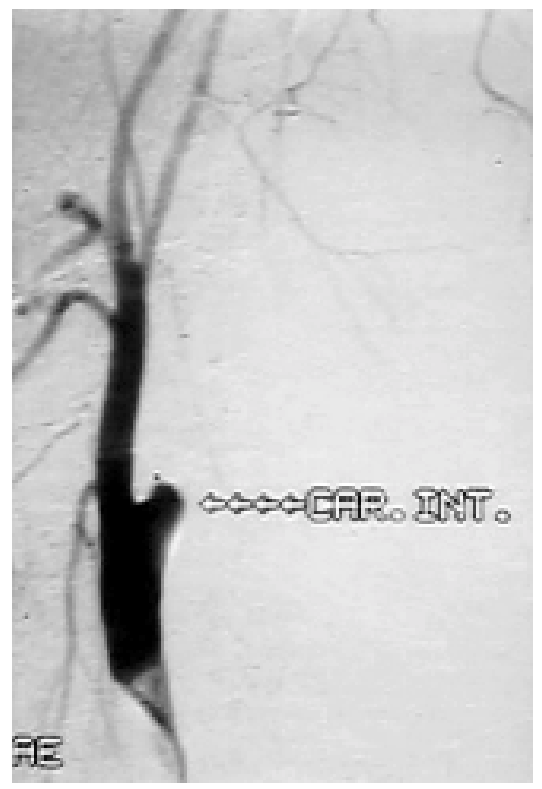

FIGURA 2

Angiografia digital cerebral (OAE), mostrando obstrução da artéria carótida interna esquerda.

cifoescoliose, pectus excavatum ou carinatum e hipermobilidade articular. Miopia e ectopia de cristalino são as manifestações oculares mais freqüentes, embora descolamento de retina possa ocorrer. Insuficiência das válvulas mitral e aórtica e dissecção da aorta são as típicas manifestações cardiovasculares dessa síndrome. As complicações cardiovasculares são a causa dos óbitos na maioria dos pacientes. Outros achados da síndrome de Marfan são pneumotórax espontâneo, por vezes bilateral ${ }^{17,18}$, hérnia inguinal e ectasia dural.

Em pacientes com síndrome de Marfan, encontramos excessiva fragilidade vascular, e o exame anatomopatológico desses vasos caracteristicamente revela necrose medial cística, freqüentemente com perda de fibras elásticas. Geralmente, é um prolongamento da dissecção da aorta, mas pode ser exclusivo das carótidas. Existem relatos de envolvimento das artérias espinhais pela dissecção da aorta com o aparecimento de paraparesia ${ }^{19}$. O comprometimento das artérias carótidas ou espinhais pode ocorrer em $10 \%$ a $20 \%$ dos pacientes com síndrome de Marfan. A tortuosidade e a ectasia arterial, como a encontrada em nosso paciente, têm sido descritas na angiografia desses pacientes, assim como em pacientes com síndrome de Ehlers-Danlos do tipo IV.

O prognóstico de pacientes com síndrome de Marfan foi alterado nos últimos 20 anos, com aumento de sobrevida de $25 \%{ }^{1,20}$. Os motivos desse aumento significativo podem ter sido causados por: 1) aumento da

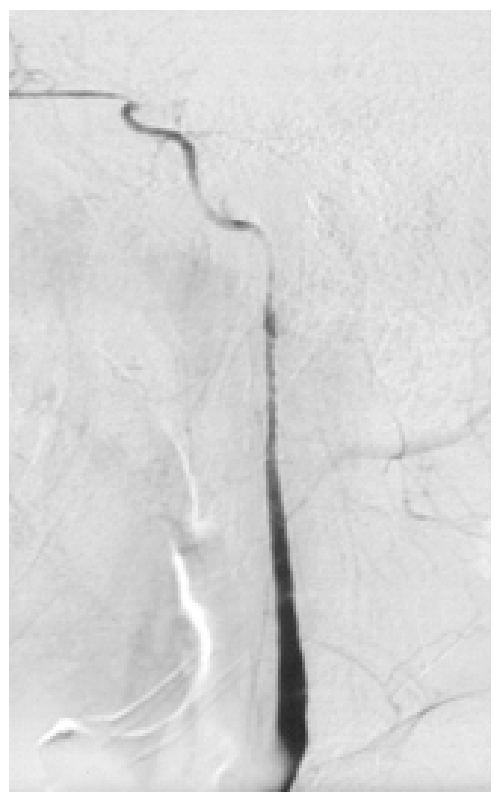

FIGURA 3

Angiografia digital cerebral (perfil), mostrando dissecção da artéria carótida interna direita.

expectativa de vida na população-geral, 2) benefícios provenientes de melhores condições da cirurgia cardíaca e vascular e 3) aumento da proporção de casos leves pela melhoria no diagnóstico. Um levantamento realizado na Inglaterra para pacientes com síndrome de Marfan encontrou uma idade média de óbito de 45,3+/- 16,5 anos ${ }^{21}$.

\section{CONCLUSÃO}

A ocorrência de dissecção espontânea da artéria carótida deve nos alertar para a possibilidade de doenças do tecido conjuntivo, dentre as quais a síndrome de Marfan, mesmo na ausência de antecedentes familiares. Os sinais clínicos fenotípicos e os antecedentes pessoais de deslocamento de cristalino, pneumotórax espontâneo podem nos auxiliar muito nesse diagnóstico.

\section{SUMMARY}

Marfan syndrome and bilateral carotid dissection

Marfan syndrome is an autosomal dominant inherited disorder of connective tissue involving mainly the skeletal, ocular, pulmonary and cardiovascular systems. We presented a case of a 16-year-old boy with Marfan syndrome who had a frontal parietal infarct. Cerebral angiography showed left internal carotid occlusion and right internal carotid narrowing seemed like a arteria dissection since its origin. We emphasize the importance of investigation of connective tissue disorders in young with arterial dissection, even without familial history of these disorders.

\section{KEYWORDS}

Marfan syndrome, arterial dissection. 


\section{Referências}

1. Gielerak G \& Wierzbicki P. Marfan's syndrome: diagnosis and treatment. Pol Merkuriusz Lek, 5(26):98-100, 1998.

2. Schievink WI, Michels VV, Piepgras DG. Neurovascular manifestations of heritable connective tissue disorders: a review. Stroke, 25:889-903, 1994.

3. Alvarez Arratia MC, Muñoz A, Martínez Camacho S, Buendía Hernández A, Attie F, Fragoso R, García Cruz D, Cantú JM. Recessive autosomal inheritance in Marfan syndrome. Arch Inst Cardiol Mex, 62(4):379-382, 1992.

4. Cerullo A; Brayda Bruno M. Neurological manifestations in Marfan's syndrome. A critical review and presentation of a case. Minerva Med, 83(5):311-318, 1992.

5. Nagatani T, Inao S, Yoshida J. Hemifacial spasm associated with Marfan's syndrome: a case report. Neurosurg Ver, 21(2-3): 152-154, 1998.

6. Cistulli PA \& Sullivan CE. Sleep apnea in Marfan's syndrome. Increased upper airway collapsibility during sleep. Chest, 108(3):631-635, 1995.

7. Verbraecken JA, Willemen M, De Cock W, Coen E, Van de Heyning $P$, De Backer W. Obstructive sleep hypopnea syndrome in a patient with Marfan syndrome treated with oxygen therapy. Respiration, 62(6):355-358, 1995.

8. Turnball HM. Alterations in arterial structure and their relation to syphilis. Q J Med, 8:201-254, 1915.

9. Schievink WI, Björnsson J, Piepgras DG. Coexistence of fibromuscular dysplasia and cystic medial necrosis in a patient with Marfan's syndrome and bilateral carotid artery dissections. Stroke, 25:2492-2496, 1994.

10. Gott VL. Antoine Marfan and his syndrome: one hundred years later. Md Med J, 47(5):247-252, 1998.

11. Sakai LY, Keene DR, Engvall E. Fibrillin, a new 350-kD glycoprotein, is a component of extracellular microfibrils. $J$ Cell Biol, 103:2499-2509, 1986.

12. Boileau C, Collod G, Bonnet D. Contribution of genetics to pathogenicity and diagnosis of Marfan syndrome. Arch Mal Coeur Vaiss, 90(12 Suppl):1707-1712, 1997.

13. Tsipouras P, Del Mastro R, Sarfarazi M, Lee B, Vitale E, Child AH, Godfrey M, Devereux RB, Hewett D, Steinmann B et al. Genetic linkage of the Marfan syndrome, ectopia lentis, and congenital contractural arachnodactyly to the fibrillin genes on chromosomes 15 and 5 . The International Marfan Syndrome Collaborative Study. N Engl J Med, 326(14):905909, 1992

14. Ramirez F, Gayraud B \& Pereira L. Marfan syndrome: new clues to genotype-phenotype correlations. Ann Med, 31(3):202-207, 1999.

15. Perez AB, Pereira LV, Brunoni D, Zatz M, Passos Bueno MR. Identification of 8 new mutations in Brazilian families with Marfan syndrome. Mutations in brief $n=211$. Hum Mutat, 13(1):84, 1999.

16. De Paepe A, Devereux RB, Dietz HC, Hennekam RC, Pyeritz RE. Revised diagnostic criteria for the Marfan syndrome. Am J Med Genet, 62(4):417-426,1996.

17. Hashimoto K, Yata Y, Miyamoto H, Morita K, Horikoshi S, Arai T. Bilateral pneumothorax and rupture of dissecting aortic aneurysm following a mitral valve replacement in Marfan syndrome: a case report. Kyobu Geka, 45:11, 1027-1030, 1992.

18. Yellin A, Shiner RJ, Lieberman Y. Familial multiple bilateral pneumothorax associated with Marfan syndrome. Chest, 100(2):577-578, 1991.

19. Spittell PC, Spittell JA Jr, Joyce JW, Tajik AJ, Edwards WD, Schaff HV, Stanton AW. Clinical features and differential diagnosis of aortic dissections: experience with 236 cases (1980 through 1990). Mayo Clin Proc, 68:642-651, 1993.

20. Silverman DI, Burton KJ, Gray J, Bosner MS, Kouchoukos NT, Roman MJ, Boxer M, Devereux RB, Tsipouras P. Life expectancy in the Marfan syndrome. Am J Cardiol, 75(2):157160, 1995.

21. Gray JR, Bridges AB, West RR, McLeish L, Stuart AG, Dean JC, Porteous ME, Boxer M, Davies SJ. Life expectancy in British Marfan syndrome populations. Clin Genet, 54(2):124128, 1998.

\section{Endereço para correspondência:}

Dr. Roberto Magalhães Carneiro de Oliveira

Unifesp-EPM - Disciplina de Neurologia

Rua Botucatu, 740 - Vila Clementimo

04023-900 - São Paulo, SP

E-mail:rmco@uol.com.br 